Check for updates

Cite this: RSC Adv., 2019, 9, 14558

Received 15th February 2019

Accepted 30th April 2019

DOI: 10.1039/c9ra01169b

rsc.li/rsc-advances

\section{Decolorization and degradation analysis of Disperse Red 3B by a consortium of the fungus Aspergillus sp. $\mathrm{XJ}-2$ and the microalgae Chlorella sorokiniana XJK}

\begin{abstract}
Weihua Tang, ${ }^{a}$ Xiaolin Xu, (DD *a Bang-Ce Ye, ${ }^{\text {D }}{ }^{\mathrm{b}}$ Peng Cao ${ }^{\mathrm{a}}$ and Asghar Ali ${ }^{\mathrm{a}}$
Disperse Red 3B, an anthraquinone dye, was decolorized by a consortium, which was constituted of the fungus (Aspergillus sp. XJ-2) and the microalgae (Chlorella sorokiniana XJK). The consortium performed better than the single system in terms of decolorization and nutrient removal simultaneously in the simulated wastewater of Dispersed Red 3B. The decolorization rate could reach $98.09 \%$ by the consortium under the optimized conditions. The removal rate of COD (Chemical Oxygen Demand), TP (Total Phosphorus), and ammonia nitrogen reached 93.9\%, 83.9\% and 87.6\%. Also, the consortium could tolerate higher salt and dye concentration than the single system did. In this co-cultural system, the lignin peroxidase and manganese peroxidase enzyme activities contributed to the degradation of Disperse Red 3B, which reached $86.7 \mathrm{U} \mathrm{L}^{-1}$ and $122.5 \mathrm{U} \mathrm{L}^{-1}$. The result of fermentation liquid analysis with UV-vis, FTIR and GC-MS showed that the colored functional group of the dye was broken and the Dispersed Red 3B was degraded into small molecular compounds with low toxicity. It was suggested that degradation plays a major role during the color removal process. The consortium exhibited greater potential in terms of color removal and water pollutant removal than the separate system did.
\end{abstract}

\section{Introduction}

From different industries such as textile, paper, photography, comic, leather, the discharge of effluent containing synthetic dyes could cause serious pollution to the environment and ecology, because the complex aromatic molecular structures of these dyes are difficult to degrade. ${ }^{1}$ Although many physicochemical processes including adsorption, advanced oxidation, photocatalysis etc. are effective to decolorize dye-containing wastewater, high cost and the formation of secondary pollutants restrict the application of these procedures. Comparatively, biological treatments with microorganisms are relatively costeffective and eco-friendly. However, traditional activated sludge could not degrade these synthetic dyes adequately, for example aromatic amines in the products can inhibit the activity of bacteria. White-rot fungi have been then intensively investigated in recent years which show strong adaptability and efficiency in the removal of certain dyes for the production of ligninolytic enzymes, including laccase, manganese peroxidase and lignin peroxidase. ${ }^{2}$ For example, $88 \%$ of Congo red was

${ }^{a}$ Key Laboratory for Green Process of Chemical Engineering of Xinjiang Bingtuan, School of Chemistry and Chemical Engineering, Shihezi University, Shihezi, 832003, People's Republic of China. E-mail: xxl_food@shzu.edu.cn

${ }^{b}$ School of Biological Engineering, East China University of Science and Technology, Shanghai, 200237, People's Republic of China decolorized by Trametes pubescens Cui 7571 cultured for 48 hours, also peak laccase activity $\left(15.783 \mathrm{U} \mathrm{mL}^{-1}\right)$, peak LiP (9.832 $\left.\mathrm{U} \mathrm{mL}^{-1}\right)$ and $\mathrm{MnP}$ activity $\left(8.647 \mathrm{U} \mathrm{mL}^{-1}\right)$ were examined during the decolorization, respectively. ${ }^{3}$ Similarity, laccase from Polyporus sp. S133 was found to be one powerful tool for the decolorization of anthraquinone dyes. ${ }^{4}$ It was demonstrated that Crude MnP from Irpex lacteus F17 could decolorize Malachite green, and its metabolites were appreciably less toxic than the parent compound. ${ }^{5}$ However, these fungal species have been only demonstrated in the degradation of particular dye. In fact, effluents from textile industry are a mixture of various organic and inorganic contaminants with high $\mathrm{COD}$ and $\mathrm{BOD}_{5}$ (Biochemical Oxygen Demand). ${ }^{6}$ The use of a microbial consortium could be useful to the bioremediation applications as a rich enzyme network and can be applied for the biodegradation of co-contaminated matrices.

It has been shown that the fungi co-culture system could greatly improve the effectivity of decolorization. Copete-Pertuz et al. reported the 1.2 times increasing of RB5 removal as the combination culture of T. viride and A. terreus, compared to monoculture. Also, the co-culture of fungi Pleurotus florida and Rhizoctonia solani resulted $98.54 \%$ of dye decolorization ratio. ${ }^{7,8}$

For the effective utilization of nitrogen, phosphorus, and other inorganic matters through the photosynthesis, microalgae were important constituent in many co-culture systems 
for the removal of contaminants from wastewater. ${ }^{9}$ Mujtaba and Lee found that co-culture system of Chlorella vulgaris and activated sludge considerably eliminated 98-100\% nitrogen, 92$100 \%$ phosphorus, and 94-96\% COD from artificial municipal wastewater. ${ }^{10}$ Consortium of the fungus Ganoderma lucidum and C. vulgaris removed COD (84.61\%), total nitrogen $(80.41 \%)$, and total phosphorus $(92.21 \%)$ respectively treating anaerobically digested swine wastewater. ${ }^{\mathbf{1 1}}$ Furthermore, filamentous fungi had a strong flocculation effect on microalgae due to their large surface area and easy solid-liquid separation, which was convenient for the recycling of microalgae. ${ }^{\mathbf{1 2}}$ Ndikubwimana et al. reported a yield of $95 \%$ for microalgae with the formation of cell pellets, ${ }^{13}$ and Prajapati et al. found A. lentulus resulting in 98\% harvesting at low glucose level $\left(5.0 \mathrm{~g} \mathrm{~L}^{-1}\right)$ within $52 \mathrm{h.}^{\mathbf{1 4}}$ In terms of economic costs, effective wastewater treatment performance and the good sources of biofuels, the co-culture system of fungi and microalgae had great potential in wastewater treatment. Generally both fungi and microalgae could decolorize dyes by the adsorption or degradation. The decolorization rate of Reactive Black 5 by $T$. versicolor strains MUM 94.04 reached $100 \%$ by adsorption and degradation. ${ }^{15}$ The decolorization rate reached $97.1 \%$ by Spirulina platensis adsorbed simulated industrial textile effluents. ${ }^{\mathbf{1 6}}$ However, the functions of each microbe in consortium are not clear during the wastewater treatment.

Aspergillus sp. is one kind of fungus with better colour removal effect on dyes. Kang et al. found Aspergillus sp. TS-A degraded $98.6 \%$ of Mordant Yellow $1 .{ }^{17}$ And Chlorella sorokiniana is one kind of microalgae with better effect on wastewater treatment. Park et al. found total nitrogen, phosphorous and glucose removal rates were $10.5 \mathrm{mg} \mathrm{L}^{-1} \mathrm{~d}^{-1}, 2 \mathrm{mg} \mathrm{\textrm {L } ^ { - 1 }} \mathrm{d}^{-1}$, $1000 \mathrm{mg} \mathrm{L}^{-1}$ respectively by Chlorella sorokiniana. ${ }^{18}$ In this work, Aspergillus sp. XJ-2 (CGMCC12963) and Chlorella sorokiniana $\mathrm{XJK}$ were chosen to the construction of consortium, both of them possessing better decolorization ability on anthraquinone dyes. ${ }^{19,20}$ Pan et al. found Aspergillus sp. XJ-2 could efficiently decolorize various anthraquinone dyes. ${ }^{19}$ Xie et al. found the decolorization rate of anthraquinone dye Disperse Blue 2BLN was $83 \%$ by Chlorella sorokiniana $\mathrm{XJK}^{20}$ In this work the consortium was used to decolorize Disperse Red 3B (one anthraquinone dye) and remove nutrients from simulated wastewater. The degradation, adsorption capacity, key enzymes responsible for degradation was analyzed, and the performance of each microbe was compared. Degradation products of Disperse Red 3B were examined by UV-vis, FTIR and GC-MS, and degradation pathways were proposed.

\section{Materials and methods}

\subsection{Dye and microorganisms}

Disperse Red 3B (1-amino-4-hydroxyl-2-phenoxyanthracene9,10-dione), one of anthraquinone dyes, was purchased from Shanghai Research and Development Biological Technology Limited Company. The structure of Disperse Red 3B is shown in Fig. 1.

Chlorella sorokiniana XJK (XJK) was a freshwater oily microalgae isolated from Keketuohai, Xinjiang Provence, China.

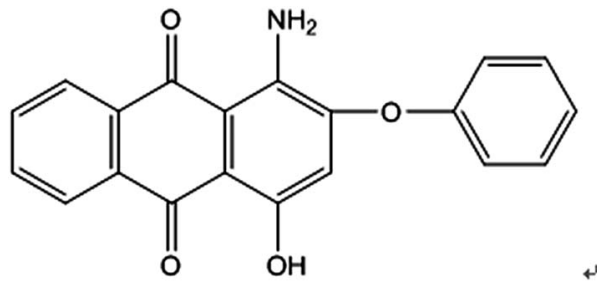

Fig. 1 Chemical structure of Disperse Red 3B.

Aspergillus sp. XJ-2 (XJ-2) was isolated from activated sludge of a textile factory in Xinjiang Provence, China. Aspergillus sp. XJ-2 and Chlorella sorokiniana XJK are conserved in Key Laboratory of Chemical Green Process of Xinjiang Corps, Chemistry and Chemical Engineering College, Shihezi University.

\subsection{Culture mediums and conditions}

The medium for Chlorella sorokiniana XJK was modified BG11 medium. ${ }^{21}$ The modified BG11 medium was formulated as follows: $5 \mathrm{~g} \mathrm{~L}^{-1}$ glucose, $0.83 \mathrm{~g} \mathrm{~L}^{-1} \mathrm{NaNO}_{3}, 0.12 \mathrm{~g} \mathrm{~L}^{-1} \mathrm{MgSO}_{4}{ }^{-}$ . $7 \mathrm{H}_{2} \mathrm{O}, 0.09 \mathrm{~g} \mathrm{~L}^{-1} \mathrm{~K}_{2} \mathrm{HPO}_{4} \cdot 3 \mathrm{H}_{2} \mathrm{O}, 0.03 \mathrm{~g} \mathrm{~L}^{-1} \mathrm{CaCl}_{2}, 0.02 \mathrm{~g} \mathrm{~L}^{-1}$ $\mathrm{NaCO}_{3}, 0.01 \mathrm{~g} \mathrm{~L}^{-1}$ citric-acid, $0.01 \mathrm{~g} \mathrm{~L}^{-1} \mathrm{Fe}\left(\mathrm{NH}_{4}\right)_{3}\left(\mathrm{C}_{6} \mathrm{H}_{5} \mathrm{O}_{7}\right)_{2}$, $0.001 \mathrm{~g} \mathrm{~L}^{-1} \mathrm{Na}_{2}$ EDTA $2 \mathrm{H}_{2} \mathrm{O}, 0.2 \mathrm{~mL} \mathrm{~L}^{-1}$ trace metal mix $(2.86 \mathrm{~g}$ $\mathrm{L}^{-1} \mathrm{H}_{3} \mathrm{BO}_{3}, 1.86 \mathrm{~g} \mathrm{~L}^{-1} \mathrm{MnCl}_{2} \cdot 4 \mathrm{H}_{2} \mathrm{O}, 0.39 \mathrm{~g} \mathrm{~L}^{-1} \mathrm{NaMoO}_{4} \cdot 2 \mathrm{H}_{2} \mathrm{O}$, $0.22 \mathrm{~g} \mathrm{~L}^{-1} \mathrm{ZnSO}_{4} \cdot 7 \mathrm{H}_{2} \mathrm{O}, 0.08 \mathrm{~g} \mathrm{~L}^{-1} \mathrm{CuSO}_{4} \cdot 5 \mathrm{H}_{2} \mathrm{O}, 0.05 \mathrm{~g} \mathrm{~L}^{-1}$ $\left.\mathrm{Co}\left(\mathrm{NO}_{3}\right)_{2} \cdot 6 \mathrm{H}_{2} \mathrm{O}\right)$. XJK was cultivated grown up under light intensity $830 \mathrm{~mol} \mathrm{~m} \mathrm{~m}^{-2} \mathrm{~s}^{-1}$ and temperature $30{ }^{\circ} \mathrm{C}$ for seven days. $^{22}$ The medium of Aspergillus sp. XJ-2 was Czapek's medium. ${ }^{19} \mathrm{XJ}-2$ was cultivated at $30^{\circ} \mathrm{C}$ and rotated in a shaker at $170 \mathrm{rpm}$ for $30 \mathrm{~h}^{23}$

\subsection{Simulated wastewater treatment}

2.3.1 Simulated wastewater. Simulated wastewater was prepared according to the actual industrial wastewater. The compositions for simulated wastewater were shown below: $0.1 \mathrm{~g}$ $\mathrm{L}^{-1}$ Disperse Red 3B, $0.38 \mathrm{~g} \mathrm{~L}^{-1} \mathrm{NH}_{4} \mathrm{Cl}, 0.08 \mathrm{~g} \mathrm{~L}^{-1} \mathrm{~K}_{2} \mathrm{HPO}_{4}$, $0.030 \mathrm{~g} \mathrm{~L}^{-1} \mathrm{KH}_{2} \mathrm{PO}_{4}, 0.248 \mathrm{~g} \mathrm{~L}^{-1} \mathrm{NaHCO}_{3}, 0.5 \mathrm{~g} \mathrm{~L}^{-1}$ glucose and $\mathrm{pH}$ 8.2. The initial levels $\left(\mathrm{g} \mathrm{L}^{-1}\right)$ were COD 0.545 , TP 0.02 , ammonia nitrogen 0.1 and initial $\mathrm{C} / \mathrm{N} / \mathrm{P} 20: 5: 1$.

2.3.2 Construction of the consortium. $10 \mathrm{~mL}$ microalgae $\left(1.5 \times 10^{6}\right.$ cell per $\left.\mathrm{mL}\right)$ were added into $100 \mathrm{~mL}$ simulated wastewater mixed in $150 \mathrm{~mL}$ flasks. Then $10 \mathrm{~mL}$ fungal spores $\left(1.5 \times 10^{6}\right.$ cell per $\left.\mathrm{mL}\right)$ were put in these flasks. The $\mathrm{pH}$ of simulated wastewater was adjusted to 7.0 and made these flasks were cultured at $30{ }^{\circ} \mathrm{C}, 170 \mathrm{rpm}$ for 4 days. In order to get an optimal co-culture system, the influences of the inoculum ratio of Aspergillus sp. XJ-2 and Chlorella sorokiniana XJK ( $1: 1,1: 2$, $1: 3,2: 1,3: 11.5 \times 10^{6}$ cell per $\left.\mathrm{mL}\right)$, inoculation time of Aspergillus sp. $\mathrm{XJ}-2$ (0, 6, 12 and $24 \mathrm{~h})$, incubation temperature $\left(20,25,30,35,40{ }^{\circ} \mathrm{C}\right), \mathrm{pH}$ of simulated wastewater $(4,5,6,7,8)$ and rotation speed $(140,150,160,170,180 \mathrm{rpm})$ on the simulated wastewater were investigated. The optimized index was the decolorization rate of simulated wastewater. The determination of decolorization rate was referenced to Kang et al. ${ }^{\mathbf{1 7}}$ (final absorbance of Disperse Red 3B at $590 \mathrm{~nm}$ ). 
2.3.3 Tolerance of dye and salt. Simulated wastewater containing dye $\left(0.1,0.2,0.3,0.4,0.5 \mathrm{~g} \mathrm{~L}^{-1}\right)$ and $\mathrm{NaCl}(0,5,10,15$, $20 \mathrm{~g} \mathrm{~L}^{-1}$ ) were decolorized by single Aspergillus sp. XJ-2 of $4.5 \times$ $10^{6}$ cell per $\mathrm{mL}$, single Chlorella sorokiniana XJK of $4.5 \times 10^{6}$ cell per $\mathrm{mL}$ and the consortium for 4 days, respectively. Decolorization rates were monitored to compare the dye concentration tolerance and salt tolerance after every $24 \mathrm{~h}$.

2.3.4 Adsorption and degradation. The influence of the four different co-culture systems on the adsorption and degradation of simulated wastewater was investigated. For this purpose, decolorization rates of simulated wastewater and biomasses of microorganisms were determined. Four different co-culture systems include the consortium of XJ-2 and XJK, the consortium of XJ-2 (inactivated) and XJK, the consortium of XJ-2 and XJK (inactivated) and the consortium of XJ-2 (inactivated) and XJK (inactivated). The inactivation condition of the microorganism was heated at $121{ }^{\circ} \mathrm{C}$ for 10 minutes. The adsorption and degradation of simulated wastewater by mixed system was calculated as follows:

$$
\mathrm{DE}=\mathrm{DA}-\mathrm{AD}
$$

DE is the degradation capacity of the consortium. DA (the decolorizing capacity of the consortium) was defined as simulated decolorization rate of wastewater when the consortium of $\mathrm{XJ}-2$ and XJK. AD (the adsorption capacity of the consortium) was defined as simulated decolorization rate of wastewater when the consortium of XJ-2 (inactivated) and XJK (inactivated).

\subsection{Analyses}

2.4.1 Dye decolorization and biomass. Simulated wastewater was treated by single Aspergillus sp. XJ-2 of $1.5 \times 10^{6}$ cell per $\mathrm{mL}$, single Chlorella sorokiniana $\mathrm{XJK}$ of $3.0 \times 10^{6}$ cell per $\mathrm{mL}$ and the consortium of the $1.5 \times 10^{6}$ cell per $\mathrm{mL} \mathrm{XJ-2}$ and $3.0 \times$ $10^{6}$ cell per $\mathrm{mL}$ XJK for 4 days, respectively. Decolorization rate and accumulation biomass of microorganism were measured to compare treatment of simulated wastewater by different microbial systems. The determination of decolorization rate was referenced to Kang et al. ${ }^{17}$ (final absorbance of Disperse Red $3 \mathrm{~B}$ at $590 \mathrm{~nm}$ ). Accumulation biomass of microorganism was measured by dry weight method. The dry weight method was referenced to Kumari et al. ${ }^{8}$

2.4.2 COD, TP and ammonia nitrogen. Simulated wastewater was degraded by single Aspergillus sp. XJ-2 of $4.5 \times 10^{6}$ cell per $\mathrm{mL}$, single $C$. sorokiniana $\mathrm{XJK}$ of $4.5 \times 10^{6}$ cell per $\mathrm{mL}$ and the consortium for 4 days, respectively. Removal of COD, total phosphorus and TN were monitored to compare the performances of pollutant removal after every $24 \mathrm{~h}$. The determination of COD, TP, and ammonia nitrogen were referenced to Guo et al. ${ }^{11}$

2.4.3 Enzyme assays. Simulated wastewater was decolorized by the consortium Aspergillus sp. XJ-2 and Chlorella sorokiniana XJK for 4 days. The fermentation solutions were extracted and centrifuged at $6500 \times g$ for $10 \mathrm{~min}$. The supernatants were used for determination of extracellular enzyme. Precipitations were frozen and grinded with liquid nitrogen and reconstituted in sodium acetate buffer $(\mathrm{pH}=5.0)$. The supernatants were obtained by centrifugation at $6500 \times g$ for $10 \mathrm{~min}$ and were used for determination of intracellular enzyme. The enzyme activities determination of MnP (manganese peroxidase) LiP (lignin peroxidase) and Lac (laccase) were referenced to Pan et $a .^{19}$ All the enzyme activities determination experiments were performed in triplicate.

2.4.4 Degradation product analysis. Disperse Red 3B of $0.1 \mathrm{~g} \mathrm{~L}^{-1}$ was decolorized by the consortium Aspergillus sp. $\mathrm{XJ}-2$ and Chlorella sorokiniana XJK for 4 days. The fermentation solutions were extracted and centrifuged at $6500 \times g$ for $10 \mathrm{~min}$. The supernatants were used for degradation product analysis.

UV-vis analysis (Spectrum lab S22pc, China): decolorization rate was monitored by scanning the spectrum between 400 and $800 \mathrm{~nm}$ using a Spectrum lab S22pc UV-vis spectrophotometer. Disperse Red 3B was used as the control. ${ }^{24}$

FTIR analysis (Magna-IR 750, Thermo Nicolet): a Magna-IR 750 FTIR spectrometer was used for the FTIR analysis of the extracted metabolites in the mid-IR region of $4000-400 \mathrm{~cm}^{-1}$ at a scan speed of 16; Disperse Red 3B was used as the control. The resolution and scan number were set at $8.0 \mathrm{~cm}^{-1}$ and 16 times, respectively. ${ }^{25}$

GC/MS analysis (Agilent Technologies Inc, USA): GC system (model 7890A, Agilent) and HP-5MS capillary column $(30 \times 0.32$ $\times 0.25$ ) combined with MS system (model $5975 \mathrm{C}$, Agilent) constituted the GC-MS system. Carrier gas was helium with carrier flow rate $0.8 \mathrm{~mL} \mathrm{~min}^{-1} .{ }^{17}$ The initial temperature was $60{ }^{\circ} \mathrm{C}$ for $1 \mathrm{~min}$, which was increased to $190{ }^{\circ} \mathrm{C}$ with $10^{\circ} \mathrm{C} \mathrm{min}{ }^{-1}$. Then the temperature was increased to $235^{\circ} \mathrm{C}$ with $3{ }^{\circ} \mathrm{C} \mathrm{min}^{-1}$. Finally the temperature was increased to $280{ }^{\circ} \mathrm{C}$ with $10^{\circ} \mathrm{C} \mathrm{min}^{-1}$ and was maintained for $5 \mathrm{~min}$. Injection port temperature was $250{ }^{\circ} \mathrm{C}$ and detector temperature was $280^{\circ} \mathrm{C}^{26}$

\section{Results and discussion}

\subsection{Simulated wastewater treatment}

3.1.1 Construction of the consortium. In order to treat dyestuff wastewater, the optimal co-culture system was constructed. The decolorization rate reached $84.8 \%$ when the inoculation ratio of $\mathrm{XJ}-2$ and $\mathrm{XJK}$ was $1: 2$ (Fig. 2a). Fig. 2b showed the decolorization rate was improved to $92.5 \%$ on the fourth day when XJ-2 was inoculated at $0 \mathrm{~h}$. Temperature and $\mathrm{pH}$ had great influence on the decolorization of simulated wastewater (Fig. 2c and d), which were $25{ }^{\circ} \mathrm{C}$ and 6. Higher rotation speed of shaker could also increase the decolorization rate of simulated wastewater (Fig. 2e). The highest decolorization rate reached $98.09 \%$ when the rotation speed of shaker was $160 \mathrm{rpm}$.

According to the above conditions, the consortium of Aspergillus sp. $\mathrm{XJ}-2$ and Chlorella sorokiniana $\mathrm{XJK}$ was constructed. The optimal conditions for the co-culture system were shown below: the inoculum ratio of Aspergillus sp. $\mathrm{XJ}-2$ and Chlorella sorokiniana XJK was $1: 2$, the inoculation time of XJ-2 was $0 \mathrm{~h}$, pH was 6 , the temperature was $25^{\circ} \mathrm{C}$ and the rotation speed of shaker was $160 \mathrm{rpm}$.

3.1.2 Morphology of the co-culture system. Fungi and microalgae could form stable spherical structures under 

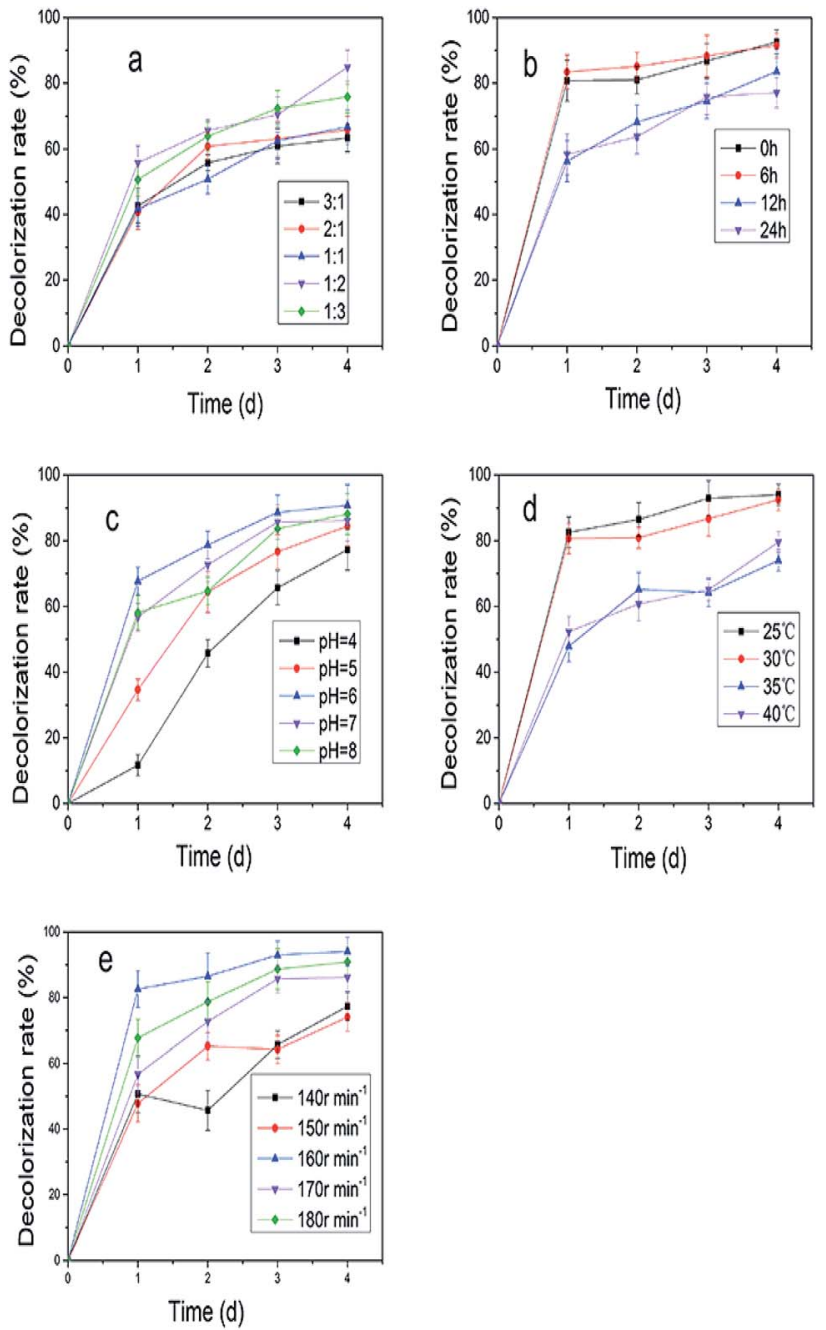

Fig. 2 Decolorization rate of simulated wastewater under different conditions. (a) Inoculation ratio of $\mathrm{XJ}-2$ and $\mathrm{XJK}$; (b) inoculation time of $\mathrm{XJ}-2$; (c) $\mathrm{pH}$; (d) temperature; (e) rotation speed of shaker.

specific conditions. Fig. 3 showed the co-culture morphology of Aspergillus sp. XJ-2 and Chlorella sorokiniana XJK when the inoculation ratio of XJ-2 and XJK was $1: 2$. Fig. 3a showed fungi and microalgae formed sphere structure. Microstructure of the consortium showed microalgae were closely intertwined with fungi by fungal hyphae (Fig. 3b). Simulation diagram of the consortium formation was described in Fig. 3c. The compact fungal-microalgae ball structure was formed by encapsulating microalgae inside the fungus by fungal hyphae. ${ }^{27}$ The $\mathrm{CO}_{2}$ produced by the fungi through aerobic respiration can provide nutrients for the growth of microalgae, while the $\mathrm{O}_{2}$ produced by microalgae through photosynthesis can provide nutrients for the growth of fungi. ${ }^{28}$ This compact ball structure may facilitate the collection of microalgae. ${ }^{\mathbf{1 4 , 1 5}}$

3.1.3 Decolorization of Disperse Red 3B. Single Aspergillus sp. XJ-2 system and single Chlorella sorokiniana XJK system exhibited poor decolorization rate with Disperse Red 3B. The influences of the microbial system (single XJ-2, single XJK, the consortium) on the simulated wastewater decolorization were

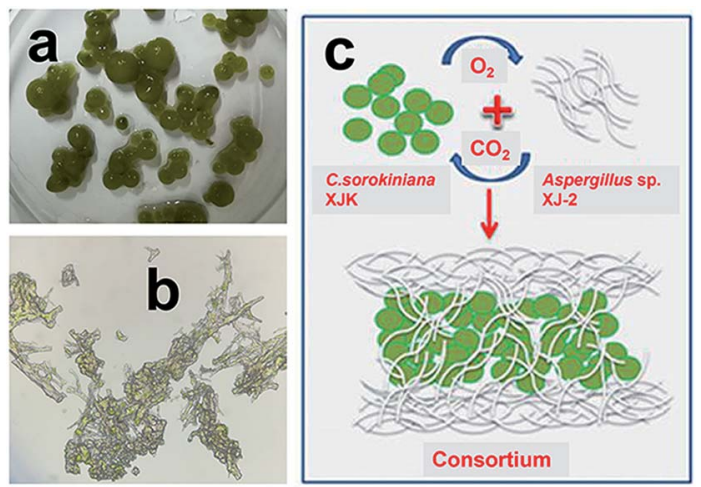

Fig. 3 Co-culture morphology of the Aspergillus sp. XJ-2 and Chlorella sorokiniana XJK. (a) Macro morphology; (b) microstructure. (c) Simulation diagram.

investigated. Fig. 4a showed the decolorization rate of the consortium on simulated wastewater was significantly better than that of the single system. Decolorization rate and biomass of microorganisms after treated simulated wastewater 4 days by single Chlorella sorokiniana $\mathrm{XJK}$, single Aspergillus sp. $\mathrm{XJ}-2$ and the consortium were shown in Fig. $4 \mathrm{~b}$. The decolorization rate of the simulated wastewater by single fungi or microalgae was below $50.0 \%$, while that of the co-culture system reached $98.09 \%$. The decolorization rate of fungi and microalgae on Disperse Red 3B was increased two times by co-culture system. After the simulated wastewater was decolorized for four days, the biomass of the fungus in the single fungal system was $0.75 \mathrm{~g}$ $\mathrm{L}^{-1}$, and the biomass of the microalgae in the microalgae system alone was $0.35 \mathrm{~g} \mathrm{~L}^{-1}$. However, the total biomass of the co-cultured microorganisms was $1.42 \mathrm{~g} \mathrm{~L}^{-1}$. This result indicated that the biomass of the co-culture system was also increased compared with the individual system microorganisms. According to biomass and decolorization, algae and fungi had a mutually beneficial relationship in the co-culture system, which was contribute to increase the decolorization rate of microorganisms on Disperse Red 3B.
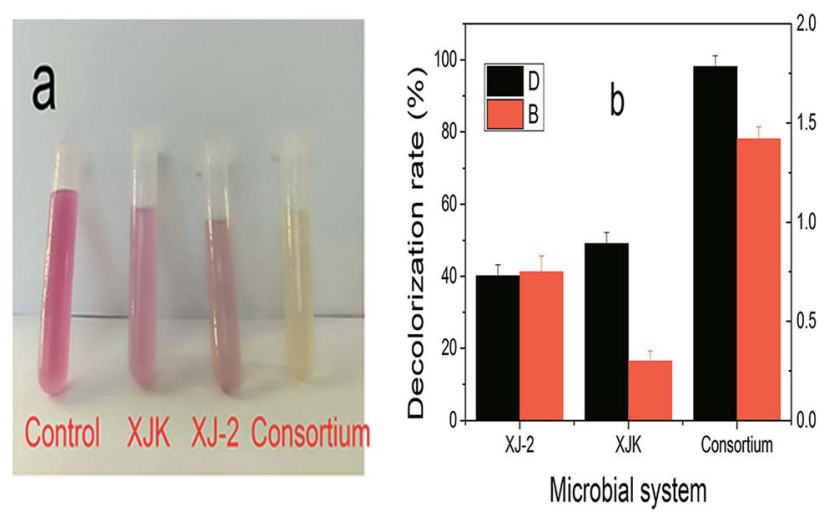

Fig. 4 Decolorization rate of simulated wastewater after 4 days treatment by single Chlorella sorokiniana XJK, single Aspergillus sp. $\mathrm{XJ}-2$ and the consortium. (a) Decolorization effect of simulated wastewater; (b) decolorization rate and biomass under used different microbial systems ( $D$ : decolorization rate; $B$ : biomass). 

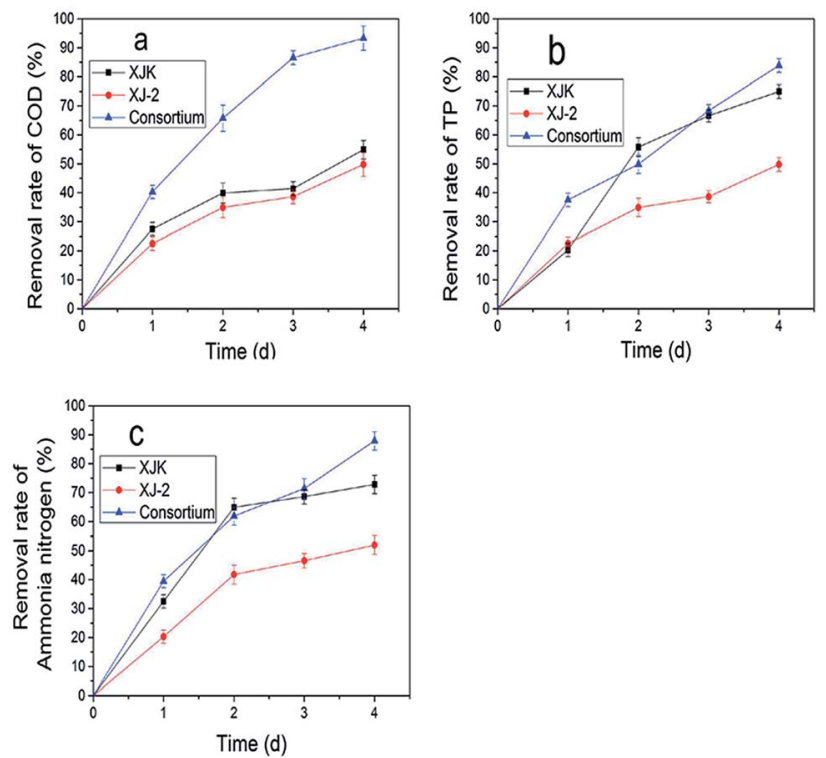

Fig. 5 The pollutant removal performances of single Chlorella sorokiniana XJK, single Aspergillus sp. XJ-2 and the consortium. (a) Removal of COD; (b) removal of TP; (c) removal of ammonia nitrogen.

3.1.4 Removal of nutrients and COD. High concentration of nitrogen, phosphorus and organic matters in wastewater can cause serious pollution of water bodies. The removal rate of nutrients and COD with single Chlorella sorokiniana XJK, single Aspergillus sp. $\mathrm{XJ}-2$ and the consortium were investigated (Fig. 5). In the simulating wastewater systems with single Chlorella sorokiniana XJK and single Aspergillus sp. XJ-2, only $54.9 \%$ and $49.8 \%$ of COD were removed after 4 days of treatment, respectively (Fig. 5a). At the same time, removal rate of COD reached $93.9 \%$ when the consortium was used to treating simulated wastewater. The removal effect of fungi and microalgae on COD was improved and nearly doubled by co-culture

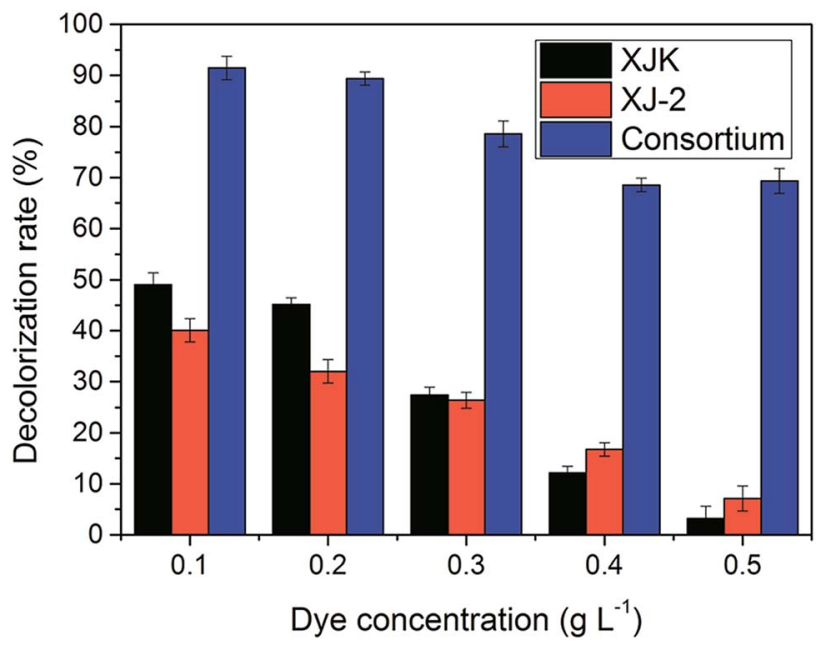

Fig. 6 Decolorization rate of single Chlorella sorokiniana XJK, single Aspergillus sp. $\mathrm{XJ}-2$ and the consortium under different dye concentrations.

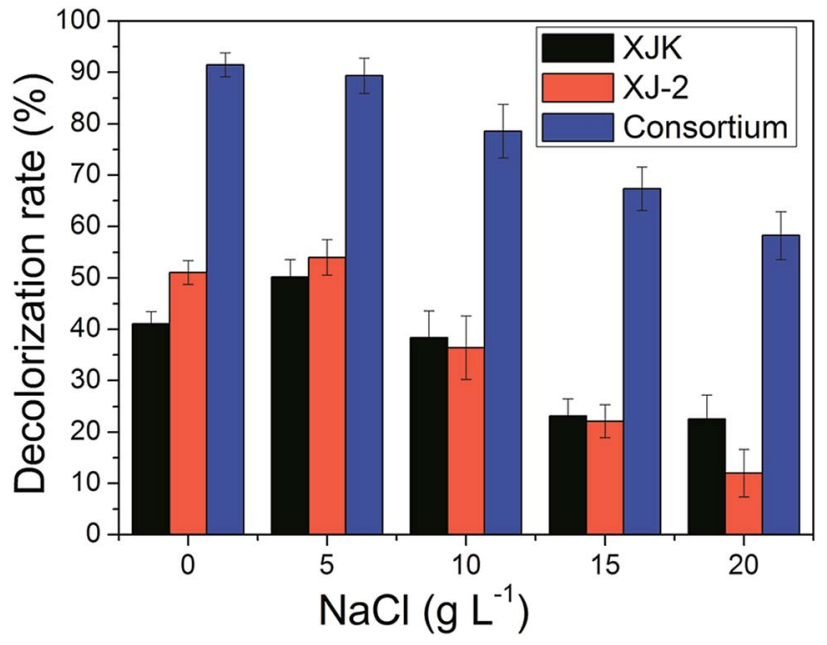

Fig. 7 Decolorization rate of simulated wastewater under different $\mathrm{NaCl}$ concentrations by single Aspergillus sp. XJ-2, single Chlorella sorokiniana XJK and the consortium.

system. The most efficient for reduction of COD was $84.61 \%$ by fungal-algal pellets treated anaerobically digested swine wastewater was shown by Guo et al. ${ }^{11}$ The removal rate of
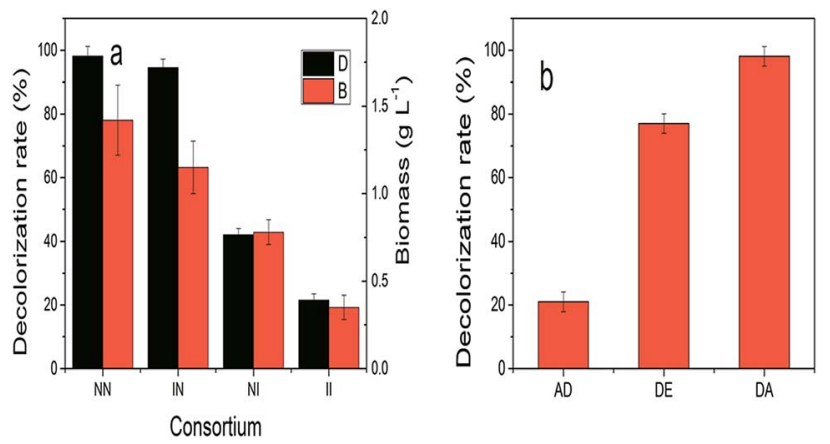

Fig. 8 Decolorization rate and microbial biomass of simulated wastewater by the consortium of XJ-2 and XJK. (a) Decolorization and biomass; (b) adsorption and degradation (NN: XJ-2 and XJK; IN: XJ-2 of inactivated and $\mathrm{XJK}$; $\mathrm{NI}: \mathrm{XJ}-2$ and $\mathrm{XJK}$ of inactivated; II: $\mathrm{XJ}-2$ of inactivated and XJK of inactivated; $A D$ : the adsorption capacity of the consortium; DE: the degradation capacity of the consortium; DA: the decolorizing capacity of the consortium).

Table 1 The ligninolytic enzyme activities as determined ${ }^{a}$

\begin{tabular}{|c|c|c|c|c|c|c|c|c|c|}
\hline \multirow{3}{*}{$\begin{array}{l}\text { Enzyme } \\
\text { activity } \\
\left(\mathrm{U} \mathrm{L}^{-1}\right)\end{array}$} & & \multicolumn{8}{|c|}{ Time (d) } \\
\hline & & \multicolumn{2}{|l|}{1} & \multicolumn{2}{|l|}{2} & \multicolumn{2}{|l|}{3} & \multicolumn{2}{|l|}{4} \\
\hline & & $\mathrm{E}$ & $\mathrm{Er}$ & E & $\mathrm{Er}$ & $\mathrm{E}$ & $\mathrm{Er}$ & $\mathrm{E}$ & $\mathrm{Er}$ \\
\hline \multirow[t]{2}{*}{ Lac } & In & 1.4 & 0.1 & 4.3 & 0.3 & 5.7 & 0.4 & 5.9 & 0.3 \\
\hline & Ex & 4.3 & 0.3 & 5.7 & 0.4 & 7.2 & 0.7 & 17.2 & 1 \\
\hline \multirow[t]{2}{*}{ Mnp } & In & 9.5 & 0.3 & 50.9 & 1.1 & 69.9 & 0.6 & 71.9 & 1.3 \\
\hline & Ex & 41.3 & 2.1 & 80.9 & 2.4 & 107.2 & 3.2 & 122.5 & 4.2 \\
\hline \multirow[t]{2}{*}{ Lip } & In & 6.7 & 0.2 & 8.9 & 0.3 & 20 & 0.4 & 40 & 0.4 \\
\hline & Ex & 6.7 & 0.1 & 28.9 & 0.4 & 60.7 & 0.9 & 86.7 & 1.1 \\
\hline
\end{tabular}

${ }^{a}$ In: intracellular; Ex: extracellular; E: mean; Er: standard deviation. 

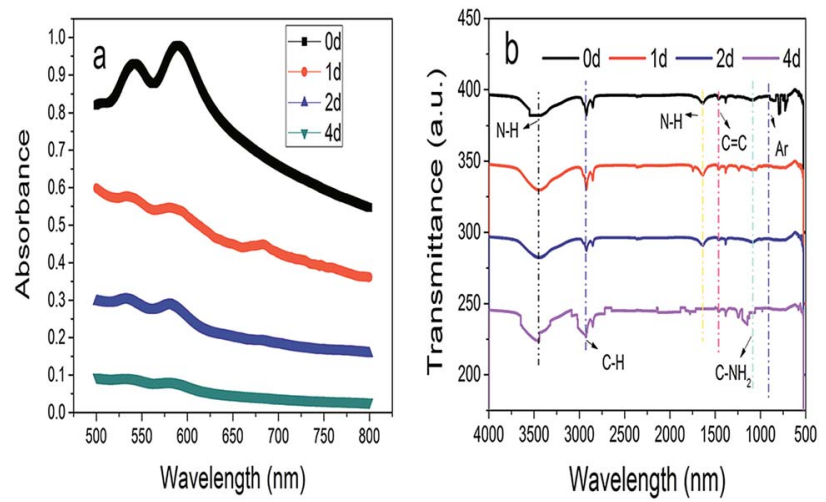

Fig. 9 Degradation products analysis of Disperse Red 3B by the consortium of Aspergillus sp. XJ-2 and Chlorella sorokiniana XJK on the first second, the second day and the fourth day. (a) UV-vis analysis; (b) FTIR analysis.

nitrogen and phosphorus with consortium was higher than that with the single system (Fig. $5 \mathrm{~b}$ and c). The removal rate of total phosphorus and ammonia nitrogen reached $83.9 \%$ and $87.6 \%$ respectively when the consortium was used to treating simulated wastewater 4 days. Efficient nutrients treatment of swine lagoon wastewater by fungal-algal pellets was also reported by Muradov et $a .^{29}$

3.1.5 Tolerance of dye. The concentration of dye in the wastewater was not fixed, so the highly-concentrated dye wastewater should also be well decolorized. Polyporus sp. S133 showed that decolorization rate of anthraquinone dyes was inversely proportional to dye concentration. ${ }^{4}$ Simulated wastewaters with different dye concentrations were treated by single Chlorella sorokiniana XJK, single Aspergillus sp. XJ2 and the consortium (Fig. 6). It was shown obviously that dye concentration tolerance was greatly improved by coculture of fungi and microalgae. Decolorization rates could reach $69.34 \%$, even when the concentration of Disperse Red 3B was $0.5 \mathrm{~g} \mathrm{~L}^{-1}$. This may suggest that the coculture system had great potential for actual wastewater treatment.

3.1.6 Salt tolerance. The salt concentration of the actual wastewater was generally high. Microorganisms with good salt tolerance are important for decolorizing dyes. The Spirulina platensis microalgae removed $94.4-99.0 \%$ of the dye mixtures containing high saline concentrations. ${ }^{16}$ In this work, $\mathrm{NaCl}$ was selected as the representative inorganic salt. Simulated wastewaters with different $\mathrm{NaCl}$ concentrations were decolorized by single microbial system and the consortium (Fig. 7). Decolorization rate was still 58.24\% when the consortium was used to decolorize simulated wastewater under the sodium chloride concentration of $20 \mathrm{~g}$ $\mathrm{L}^{-1}$. Single system had almost no discoloration in high salinity simulated wastewater. It showed that the co-culture system had higher biological activity for high salinity wastewater treatment.

Table 2 GC-MS analysis of dye degradation products

\begin{tabular}{|c|c|c|c|c|}
\hline Product & Chemical structure & Formula & $\begin{array}{l}\text { Molecular } \\
\text { weight }\end{array}$ & Incubation time (d) \\
\hline Disperse Red 3B & & $\mathrm{C}_{20} \mathrm{H}_{13} \mathrm{NO}_{4}$ & 331 & 0 \\
\hline Diisobutyl phthalate & & $\mathrm{C}_{16} \mathrm{H}_{22} \mathrm{O}_{4}$ & 278 & 2 \\
\hline 4-Hydroxy-2-butan-one & & $\mathrm{C}_{4} \mathrm{H}_{8} \mathrm{O}_{2}$ & 88 & 3 \\
\hline Acetone & & $\mathrm{C}_{3} \mathrm{H}_{6} \mathrm{O}$ & 58 & 3 \\
\hline $\mathrm{CO}_{2}$ & $=0$ & $\mathrm{CO}_{2}$ & 44 & 4 \\
\hline
\end{tabular}


According to these results, the consortium of Aspergillus sp. $\mathrm{XJ}-2$ and Chlorella sorokiniana XJK could have a great advantage over the single system in the treatment of simulated wastewater.

\subsection{Degradation pathway analysis}

3.2.1 Adsorption and degradation. The way of microbial removal of dyes was generally adsorption or degradation. The most efficient for decolorization rate was $97.1 \%$ by Spirulina platensis microalgae adsorbed simulated industrial textile effluents was shown by Cardoso et al. ${ }^{16}$ Ottoni et al. found the decolorization of Reactive Black 5 by $T$. versicolor strains MUM 94.04 reached $100 \%$ by adsorption and degradation. ${ }^{15}$ Decolorization rate and biomass of consortium were showed in Fig. 8 after 4 days treatment. The decolorization rate of the simulated wastewater by the co-culture system was $98.09 \%$ (Fig. 8a). When the fungus was inactivated, the decolorization rate of the simulated wastewater by the co-culture system was remain at 94.5\%. However, the decolorization rate dropped to $42.1 \%$ when the microalga was inactivated. It indicated that microalgae played a key role in the co-culture system, and fungi may act as an immobilization carrier. According to the change of biomass, fungi and microalgae can indeed increase biomass by co-culture. This mutual promotion was conducive to the treatment of wastewater. The degradation capacity of the consortium was $77.04 \%$ and the adsorption capacity of the consortium was $21.50 \%$ (Fig. $8 \mathrm{a}$ and b).

3.2.2 Enzyme assays. Lignin decomposing enzymes were key enzymes for dyestuff degradation. Table 1 showed ligninolytic enzymes activities during the decolorization of Disperse Red 3B by the consortium of Aspergillus sp. XJ-2 and Chlorella sorokiniana XJK. The extracellular and intracellular contents of laccase, lignin peroxidase and manganese peroxidase were measured respectively. Extracellular enzyme activity was higher than intracellular enzyme activity (Table 1). The enzyme activity of lignin peroxidase and manganese peroxidase reached $86.7 \mathrm{U} \mathrm{L}^{-1}$ and $122.5 \mathrm{U} \mathrm{L}^{-1}$ after four days, while the activity of laccase was only $17.2 \mathrm{U} \mathrm{L}^{-1}$. During the decolorization of Amaranth Red by Trametes meyenii, lignin peroxidase activity was almost zero, while laccase and manganese peroxidase were more active. ${ }^{30}$ It could be estimated that lignin peroxidase and manganese peroxidase were key enzymes in the decolorization of Disperse Red 3B.

3.2.3 UV-vis analysis. The ultraviolet full-wavelength scanning analysis of the reaction product of Disperse Red 3B by the consortium of Aspergillus sp. XJ-2 and Chlorella sorokiniana XJK on the first, second and fourth day was shown in Fig. 9a. The maximum absorption peak at $590 \mathrm{~nm}$ became weak gradually until it completely disappeared on fourth day. Therefore, it can be presumed that Dispersed Red 3B was degraded or adsorbed by the consortium of Aspergillus sp. $\mathrm{XJ}-2$ and Chlorella sorokiniana XJK.

3.2.4 FTIR analysis. FTIR analysis of degradation products on the first, second and fourth day was shown in Fig. 9b. The absorption peak at $797.3 \mathrm{~cm}^{-1}$ weakened gradually until it disappeared indicating that the aromatic ring structure was broken. The absorption peaks of $1058.9 \mathrm{~cm}^{-1}, 2922.34 \mathrm{~cm}^{-1}$ and $3441.4 \mathrm{~cm}^{-1}$ became strong gradually, which were formed by irregular stretching and vibration of $\mathrm{C}-\mathrm{NH}_{2}, \mathrm{C}-\mathrm{H}$ and $\mathrm{N}-\mathrm{H}$ respectively. The absorption peak of $1632.5 \mathrm{~cm}^{-1}$ was slowly weakened, which was formed by the stretching and vibration of $\mathrm{C}=\mathrm{O}$ and $\mathrm{C}=\mathrm{C}$. Moreover, it could be understood that many new peaks were formed on the fourth day. Therefore, it could be inferred that the Dispersed Red 3B was degraded by the optimized consortium to form some small molecule compound.

3.2.5 GC-MS analysis. GC-MS analysis of Disperse Red 3B degradation product is shown in Table 2 and Fig. 10 seven kinds of reaction products had been detected (Table 2 and Fig. 10), which were diisobutyl phthalate, guaiacol, $\mathrm{NH}_{3}, o$-xylene, acetone, 4-hydroxy-2-butanone and $\mathrm{CO}_{2}$. In this work, lignin peroxidase and manganese peroxidase may play a key role in the decolorization of Disperse Red 3B. LiP can oxidize electron-rich aromatic compounds. It oxidized an electron taken from the benzene ring of the aromatic compound into a radical when it attacked the substrate by the electron transporter. Then the major bond was cleaved in the substrate molecule and a series of cleavage reactions occurred with the chain reaction producing many different free radicals. ${ }^{30}$ Besides, Yang et al.

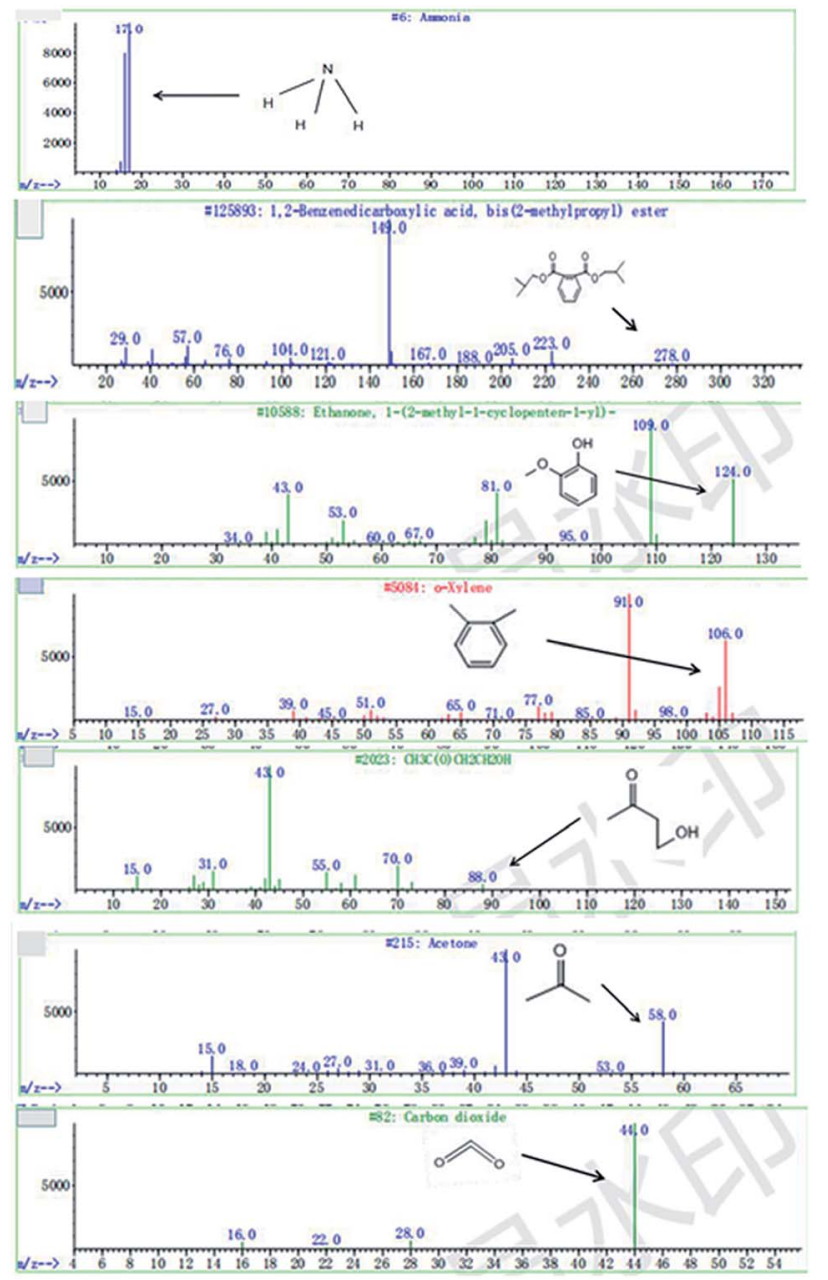

Fig. 10 GC-MS analysis of degradation products about Disperse Red 3B. 


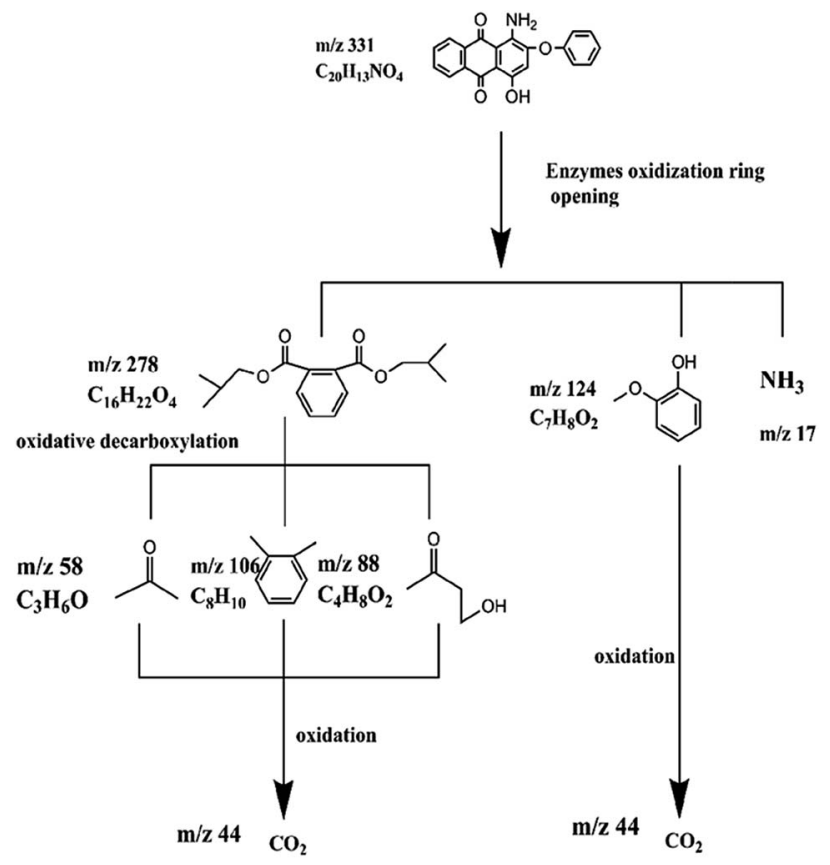

Fig. 11 Degradation pathway analysis of Disperse Red 3B.

proposed that manganese peroxidase secreted by Irpex lacteus F17 could decolorize malachite green through n-terminal demethylation and oxidation fracture of $\mathrm{C}=\mathrm{C}$ double bond. ${ }^{5}$ While Disperse Blue 2BLN was degradation, Xie and Pan et al. suggested that the weaker the bonding sequence was, the more easily the bond was destroyed..$^{19,20}$ The presumed degradation pathway was shown in Fig. 11. First, Disperse Red 3B was degraded into $\mathrm{NH}_{3}$, diisobutyl phthalate and guaiacol due to the two hetero cyclic were broken in the middle. Then, diisobutyl phthalate was degraded into $o$-xylene, acetone and 4-hydroxy-2butanone by oxidative decarboxylation. Finally, all intermediate reaction products were degraded into $\mathrm{CO}_{2}$ and other final products.

\section{Conclusions}

In this work, the consortium of the fungus Aspergillus sp. XJ-2 and the microalgae Chlorella sorokiniana XJK was constructed. The consortium exhibited stronger efficiency in terms of decolorization, COD removal and nutrients removal than the single system did. The consortium could adapt to wastewater with higher dye and higher salt concentration. The result of fermentation liquid analysis showed that Dispersed Red 3B eventually was mineralized. The consortium existed great potential to adapt to wastewater of different types and sources.

\section{Conflicts of interest}

There are no conflicts to declare.

\section{Acknowledgements}

This work was funded by the National Natural Science Foundation of China (grant number 21466032). And this work was also partially supported by Scientific Research Foundation for Changjiang Scholars of Shihezi University (grant number CJXZ201501).

\section{References}

1 M. C. Tomei, D. M. Angelucci and A. J. Daugulis, Sci. Total Environ., 2016, 573, 585-593.

2 S. Popli and U. D. Patel, Int. J. Environ. Sci. Technol., 2015, 12, 405-420.

3 J. Si, B.-K. Cui and Y.-C. Dai, Ann. Microbiol., 2013, 63, 10991108.

4 T. Hadibarata, A. R. M. Yusoff and R. A. Kristanti, Water, Air, Soil Pollut., 2012, 223, 933-941.

5 P. Yang, W. Shi, H. Wang and H. Liu, Braz. J. Microbiol., 2016, 47, 828-834.

6 R. G. Saratale, S. S. Gandhi, M. V. Purankar, M. B. Kurade, S. P. Govindwar, S. E. Oh and G. D. Saratale, J. Biosci. Bioeng., 2013, 115, 658-667.

7 L. S. Copete-Pertuz, F. Alandete-Novoa, J. Plácido, G. A. Correa-Londoño and A. L. Mora-Martínez, Sci. Total Environ., 2019, 646, 1536-1545.

8 S. Kumari and R. Naraian, J. Environ. Manage., 2016, 180, 172-179.

9 C. Tsioptsias, G. Lionta and P. Samaras, Environ. Technol., 2017, 38, 1120-1126.

10 G. Mujtaba and K. Lee, Water Res., 2017, 120, 174-184.

11 G. Guo, W. Cao, S. Sun, Y. Zhao and C. Hu, J. Appl. Phycol., 2017, 29, 2857-2866.

12 A. Bhattacharya, M. Mathur, P. Kumar, S. K. Prajapati and A. Malik, Algal Res., 2017, 21, 42-51.

13 T. Ndikubwimana, X. Zeng, Y. Liu, J.-S. Chang and Y. Lu, Algal Res., 2014, 6, 186-193.

14 S. K. Prajapati, P. Kumar, A. Malik and P. Choudhary, BioEnergy Res., 2014, 7, 1430-1440.

15 C. A. Ottoni, C. Santos, Z. Kozakiewicz and N. Lima, Folia Microbiol., 2013, 58, 187-193.

16 N. F. Cardoso, E. C. Lima, B. Royer, M. V. Bach, G. L. Dotto, L. A. Pinto and T. Calvete, J. Hazard. Mater., 2012, 241, 146153.

17 Y. Kang, X. Xu, H. Pan, J. Tian, W. Tang and S. Liu, Bioengineered, 2018, 9, 222-232.

18 J.-E. Park, Y.-B. Cho, S. Zhang and S.-J. Hwang, Journal of Korean Society of Water and Wastewater, 2013, 27, 703-709.

19 H. Pan, X. Xu, Z. Wen, Y. Kang, X. Wang, Y. Ren and D. Huang, Bioengineered, 2017, 8, 630-641.

20 L. Xie, L. Zhou, T. Liu and X. Xu, RSC Adv., 2016, 6, 106935106944.

21 L. Jiang, L. Zhang, C. Nie and H. Pei, Biotechnol. Biofuels, 2018, 11, 68.

22 S. K. Prajapati, P. Kaushik, A. Malik and V. K. Vijay, Bioresour. Technol., 2013, 135, 232-238. 
23 M. N. Aydogan and N. P. Arslan, Desalin. Water Treat., 2015, 56, 2258-2266.

24 J. P. Rodriguez, D. E. Williams, I. D. Sabater, R. C. BonugliSantos, L. D. Sette, R. J. Andersen and R. G. Berlinck, RSC Adv., 2015, 5, 66360-66366.

25 S. Ilk, D. Demircan, S. SAĞLAM, N. SAĞLAM and Z. M. Rzayev, Turk. J. Chem., 2016, 40, 262-276.

26 D. Rajkumar, B. J. Song and J. G. Kim, Dyes Pigm., 2007, 72, 1-7.
27 Y. Li, Y. Xu, L. Liu, P. Li, Y. Yan, T. Chen, T. Zheng and H. Wang, Algal Res., 2017, 25, 402-412.

28 W. Zhou, Y. Cheng, Y. Li, Y. Wan, Y. Liu, X. Lin and R. Ruan, Appl. Biochem. Biotechnol., 2012, 167, 214-228.

29 N. Muradov, M. Taha, A. F. Miranda, D. Wrede, K. Kadali, A. Gujar, T. Stevenson, A. S. Ball and A. Mouradov, Biotechnol. Biofuels, 2015, 8, 24.

30 P. R. Chenaux, N. Lalji and D. D. Lefebvre, AMB Express, 2014, 4, 74 . 